\title{
Omeprazole increases survival via different mechanisms in two rat models of liver injury
}

\author{
Masaya Kotsuka ( $\nabla$ kotsukam@hirakata.kmu.ac.jp ) \\ Kansai Medical University \\ Yuki Hashimoto \\ Kansai Medical University \\ Richi Nakatake \\ RWTH Aachen University \\ Tetsuya Okuyama \\ Kansai Medical University \\ Masahiko Hatta \\ Kansai Medical University \\ Terufumi Yoshida \\ Kansai Medical University \\ Tadayoshi Okumura \\ Kansai Medical University \\ Mikio Nishizawa \\ Ritsumeikan University \\ Masaki Kaibori \\ Kansai Medical University \\ Mitsugu Sekimoto \\ Kansai Medical University
}

\section{Research Article}

Keywords: Proton Pump Inhibitor, Gastric Acid Secretion, D-galactosamine treatment, Hepatectomy, iNOS Induction, Inflammatory Mediators, LPS-induced Liver Injury

Posted Date: May 12th, 2021

DOI: https://doi.org/10.21203/rs.3.rs-442122/v1

License: (c) (i) This work is licensed under a Creative Commons Attribution 4.0 International License. Read Full License 


\section{Abstract}

Omeprazole (OMZ) is a proton pump inhibitor (PPI) that is used to reduce gastric acid secretion, but little is known about its possible liver protective effects. This study investigated whether OMZ has beneficial effects in rat septic models of lipopolysaccharide (LPS)-induced liver injury after D-galactosamine (GalN) treatment and 70\% hepatectomy (PH), and to determine the mechanisms of $\mathrm{OMZ}$ in an in vitro model of liver injury. In the in vivo models, the effects of $\mathrm{OMZ}$ were examined $1 \mathrm{~h}$ before treatment. $\mathrm{OMZ}$ increased survival and decreased tumor necrosis factor-alpha, inducible nitric oxide synthase, cytokine-induced neutrophil chemoattractant 1, interleukin (IL)-6, and IL-1 $\beta$ mRNA expression, and increased IL-10 mRNA expression in the livers of both GaIN/LPS- and PH/LPS-treated rats. Necrosis and apoptosis were inhibited by OMZ in GaIN/LPS rats, but OMZ had no effects on necrosis in PH/LPS rats. Primary rat hepatocytes were treated with IL1- $\beta$ in the presence or absence of OMZ (in vitro model). OMZ inhibited iNOS induction partially through suppression of NF-KB signaling in hepatocytes. Furthermore, OMZ inhibited the induction of several inflammatory mediators, resulting in the prevention of LPS-induced liver injury after GalN liver failure and $\mathrm{PH}$, although $\mathrm{OMZ}$ showed different doses and mechanisms in the two models.

\section{Introduction}

Sepsis is a condition in which the dysfunction of various organs such as the liver, heart, lungs, and kidneys occurs as a result of an infectious disease. Sepsis is characterized by systemic inflammatory responses induced by infection ${ }^{1}$. A particularly severe form of sepsis that presents with severe circulation and abnormal cell metabolism is "septic shock." Infection with Gram-negative bacteria leads to excess bacterial endotoxin (lipopolysaccharide, LPS), endotoxemia, in the blood. In Japanese intensive care units, frequent sites of infection are the pulmonary and intra-abdominal regions in severe sepsis patients ${ }^{2}$.

The incidence sepsis has gradually increased. Over the last decade, the number of reported sepsis diagnoses in the emergency department has tripled, exceeding the number of diagnoses of myocardial infarction. The reason for this increase is thought to be aging and the advancement of medical care. Many older people suffer from chronic disease and are susceptible to infectious diseases that are likely to become severe. In addition, with the progress of medical treatment, the number of cases in which treatments that suppress immunity are applied is increasing with the rise in transplant surgery and chemotherapy for cancer. Furthermore, patients treated for immunosuppression are more susceptible to infections. Most importantly for patient outcome, early diagnosis of sepsis and effective antibiotic treatment are essential.

There are several experimental animal models of endotoxemia and sepsis with liver failure, including two that we reported previously: simultaneous administration of D-galactosamine and LPS (GaIN/LPS) ${ }^{3-5}$ and a partial (70\%) hepatectomy followed by LPS administration (PH/LPS) ${ }^{6,7}$. In our previous studies, high doses of LPS, such as $\geq 50 \mu \mathrm{g} / \mathrm{kg}$ and $\geq 250 \mu \mathrm{g} / \mathrm{kg}$, resulted in poor survival (less than $10 \%$ ) in two 
models of GalN/LPS and PH/LPS, respectively. In this study, we decreased the levels of LPS injected after GalN and PH treatment to closely reflect the conditions in human cases.

In both sepsis models, nitric oxide (NO)/inducible nitric oxide synthase (iNOS) and inflammatory mediators such as tumor necrosis factor-alpha (TNF-a), interleukin-1 $\beta$ (IL-1 $\beta)$, and cytokine-induced neutrophil chemoattractant 1/chemokine (C-X-C motif) ligand 1 (CINC-1/CXCL-1) (IL-8 rat analogue) are excessively induced in hepatocytes within $3 \mathrm{~h}$ of LPS injection ${ }^{3-7}$. Excessive NO production by iNOS contributes to liver injury 8,9 .

Omeprazole (OMZ), the first clinically approved proton pump inhibitor (PPI), is a substituted benzimidazole that interacts with the gastric proton pump $\left(\mathrm{H}^{+}, \mathrm{K}^{+}\right.$-ATPase $)$in the secretory membrane, resulting in potent long-acting inhibition of gastric acid secretion ${ }^{10-12}$, and it is extensively metabolized by the liver ${ }^{13}$. PPIs inhibit hydrogen potassium adenosine triphosphatase, which in turn leads to reduced gastric acid secretion from parietal cells ${ }^{14}$. Many studies have proposed other mechanisms by which PPIs exert their anti-inflammatory effects ${ }^{15-24}$. PPIs were demonstrated to be a revolutionary treatment for acid-related diseases, and they minimized the need for elective surgery for ulcers or reflux when introduced to clinical practice 25,26 .

Previously, we reported the liver-protective effects of lansoprazole (LPZ) ${ }^{5}$, a PPI. However, few studies have examined whether other PPIs influence the expression of proinflammatory mediators and survival in animal models of liver injury or septic shock. In this study, we investigated the hepatoprotection of OMZ in in vivo and in vitro models. We first used two rat models of liver injury induced with GaIN/LPS or $\mathrm{PH} /$ LPS and examined if OMZ influences survival and various inflammatory mediators. Next, to determine the mechanisms of these hepatoprotective effects, we examined if OMZ inhibits iNOS induction and NO production in primary cultured rat hepatocytes ${ }^{27}$.

\section{Results}

Effects of LPS on survival in rat GaIN/LPS and PH/LPS models. Previously, we applied GalN (500 $\mathrm{mg} / \mathrm{kg}) / \mathrm{LPS}(50 \mu \mathrm{g} / \mathrm{kg})$ and PH (70\% hepatectomy)/LPS $(250 \mu \mathrm{g} / \mathrm{kg})$ in two rat liver injury (septic) models ${ }^{5,28,29}$. In the GalN/LPS model, a mixture of GaIN and LPS was simultaneously injected into the penile vein (intravenously, i.v.), while LPS was injected into the penile vein (i.v.) 2 days after $70 \%$ hepatectomy in the PH/LPS model. More than $90 \%$ of rats had died $72 \mathrm{~h}$ after GaIN/LPS or LPS injection in these models. In the current study, we examined the effects of lower doses of LPS on survival without changing other conditions to obtain milder survival curves.

In the GalN/LPS model, $0.5-50 \mu \mathrm{g} / \mathrm{kg}$ LPS was injected with GalN (500 mg/ $\mathrm{kg})$. Cumulative survival was 0 with $2.5-50 \mu \mathrm{g} / \mathrm{kg}$ LPS (Fig. 1A), whereas it varied (approximately $0.2 ; \mathrm{n}=13$ ) with $0.5 \mu \mathrm{g} / \mathrm{kg}$ LPS. Therefore, we used $2.5 \mu \mathrm{g} / \mathrm{kg}$ LPS in the GalN/LPS model as the positive control (PC). Similarly, we examined cumulative survival with $6.25-250 \mu \mathrm{g} / \mathrm{kg}$ LPS (Fig. 1B) in the PH/LPS model. We determined 
that $25 \mu \mathrm{g} / \mathrm{kg}$ LPS (cumulative survival curves, 0.2-0.3) was the most appropriate dose for further experiments in the PH/LPS model, but it varied (approximately $0.4 ; n=10$ ) with $6.25 \mu \mathrm{g} / \mathrm{kg}$ LPS.

Effects of omeprazole on increased survival in rat GaIN/LPS and PH/LPS models. OMZ is a potent PPI of $\mathrm{H}^{+}$-ATPase in gastric parietal cells and is widely used for the treatment of peptic ulcer disease and reflux esophagitis ${ }^{30}$. Approximately half of an oral dose of $\mathrm{OMZ}$ is systemically available because of substantial first-pass elimination by the liver ${ }^{13}$. OMZ has been shown to be metabolized by the cytochrome P450 enzymes 3A4 (CYP3A4) and 2C19 (CYP2C19), ${ }^{31}$ and the major metabolites found in plasma are hydroxy $\mathrm{OMZ}$ and $\mathrm{OMZ}$ sulfone ${ }^{13}$.

In the GalN/LPS $(2.5 \mu \mathrm{g} / \mathrm{kg})$ model, rats were treated with 40,80 , and $120 \mathrm{mg} / \mathrm{kg}$ OMZ (intraperitoneally, i.p.) for $1 \mathrm{~h}$ before GaIN/LPS injection (PC); no significant effects on survival were observed. However, two injections (second injection was administered $3 \mathrm{~h}$ after GalN/LPS) of $120 \mathrm{mg} / \mathrm{kg}$ OMZ increased survival (Fig. 2A1). One injection of higher-dose OMZ (180 and $240 \mathrm{mg} / \mathrm{kg}$ ) increased survival, although $240 \mathrm{mg} / \mathrm{kg}$ OMZ had no effect compared with $180 \mathrm{mg} / \mathrm{kg}$, indicating that adverse effects might occur by overdosing (Fig. 2A2). In the PH/LPS ( $25 \mu \mathrm{g} / \mathrm{kg}$ ) model (PC), $100 \mathrm{mg} / \mathrm{kg}$ OMZ (i.p., $1 \mathrm{~h}$ before LPS injection) significantly increased survival (Fig. 2B).

In the subsequent biochemical and histopathological analyses, OMZ $(180 \mathrm{mg} / \mathrm{kg})$ was used in the GalN $(500 \mathrm{mg} / \mathrm{kg}) / \mathrm{LPS}(2.5 \mu \mathrm{g} / \mathrm{kg})$ rat model (Fig. $2 \mathrm{~A} 2)$ and OMZ $(100 \mathrm{mg} / \mathrm{kg})$ was used in the PH/LPS (25 $\mu \mathrm{g} / \mathrm{kg}$ ) rat model (Fig. 2B).

Effects of omeprazole on nuclear factor (NF)-KB activation in the livers of rat liver injury models. In the GalN $(500 \mathrm{mg} / \mathrm{kg}) / \mathrm{LPS}(2.5 \mu \mathrm{g} / \mathrm{kg})$ and PH/LPS $(25 \mu \mathrm{g} / \mathrm{kg})$ models, electrophoretic mobility shift assay (EMSA) experiments revealed that OMZ $(180 \mathrm{mg} / \mathrm{kg}$ and $100 \mathrm{mg} / \mathrm{kg})$ inhibited the activation of NF-KB at both 1 and $6 \mathrm{~h}$ in GalN/LPS rats (Fig. 3A) and at $1 \mathrm{~h}$ in PH/LPS rats (Fig. 3B), respectively. However, LPS had less effect on NF-KB activation at $4 \mathrm{~h}$ in PH/LPS rats.

Effects of omeprazole on mRNA expression of inflammatory mediators in the livers of rat liver injury models. In the GalN/LPS model, OMZ decreased the mRNA levels of TNF-a (1 h), iNOS (6 h), CINC-1 (1 h), IL-6 (6 h), and IL-1 $\beta$ ( $6 \mathrm{~h}$ ), but increased IL-10 (1 and $6 \mathrm{~h}$ ), compared with the positive control (Fig. 4A). In the PH/LPS model, OMZ also decreased the mRNA levels of TNF- $\mathrm{a}(1$ and $4 \mathrm{~h}$ ), iNOS (4 h), CINC-1 ( $1 \mathrm{~h}$

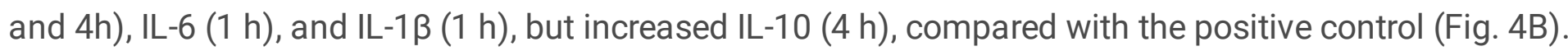

Effects of omeprazole on nitric oxide, alanine/aspartate transaminase (ALT/AST), and cytokines in the serum of rat GalN/LPS and PH/LPS models. In the GalN/LPS model, OMZ decreased NO production (6 h), ALT/AST ( 6 h), TNF-a (1 and 6 h), IL-6 ( 6 h), and IL-1 $\beta$ ( 6 h) compared with the positive control (Fig.5A). In the PH/LPS model, OMZ also decreased NO production ( $4 \mathrm{~h}$ ), ALT/AST (4 h), TNF-a (1 and 4 h), IL-6 (4 h), and IL-1 3 (1 and $4 \mathrm{~h}$ ) compared with the positive control (Fig. 5B).

Effects of omeprazole on pathological changes in the livers of GaIN/LPS and PH/LPS models. In both rat models, the areas of focal necrosis with inflammatory cell infiltration and massive hemorrhage were 
increased in the positive controls at 1 and $6 \mathrm{~h}$ (or $4 \mathrm{~h}$ ), while it was reduced by OMZ at 1 and $6 \mathrm{~h}$ (or $4 \mathrm{~h}$ ) (Fig. 6). In myeloperoxidase (MPO) staining (necrosis), OMZ decreased MPO-positive cells compared with the positive controls in both models (Fig. 6; B5 and E5). In terminal deoxynucleotidyl transferasemediated deoxyuridine triphosphate-digoxigenin nick-end labeling (TUNEL) staining (apoptosis), OMZ also decreased TUNEL-positive cells as compared with the positive controls at $6 \mathrm{~h}$ in the GalN/LPS model (Fig. 6; C3), but no differences were observed with OMZ in the PH/LPS models (Fig. 6; F3).

Next, we examined the mechanisms by which $\mathrm{OMZ}$ promoted these hepatoprotective effects in primary cultured rat hepatocytes stimulated with IL-1 $\beta$ to represent an in vitro model of liver injury ${ }^{27}$. In the liver during inflammation, in addition to the production of various inflammatory cytokines, the induction of iNOS gene expression is enhanced. Overproduction of NO by iNOS is considered a hepatic disorder, and suppression of iNOS induction is important for the alleviation of hepatic injuries. We demonstrated that NO produced by iNOS was an index of liver damage. We analyzed the organ-protective effects of various clinical drugs, conventional therapeutic drugs, herbal medicines, and functional drugs. Drugs showing inhibition of iNOS induction/NO production were examined in septic animal models to confirm their protective effects on survival.

\section{Effects of omeprazole on nitric oxide production, iNOS protein expression, and inflammatory mediator mRNA expression in primary cultured rat hepatocytes. IL-1 $\beta$ stimulates iNOS mRNA/protein expression} and NO production in primary cultured rat hepatocytes ${ }^{32}$. In this study, IL-1 $\beta$ also stimulated the expression of pro-inflammatory cytokines and chemokines such as TNF-a, IL-1 $\beta$, and CINC-1.

In primary cultured rat hepatocytes, OMZ inhibited the production of nitric oxide (NO) (Fig. 7A, upper) and the expression of iNOS protein (Fig. 7A, middle) in a dose-dependent manner. OMZ showed no cellular toxicity at the indicated concentrations, as evaluated by lactate dehydrogenase (LDH) release and trypan blue exclusion (data not shown). OMZ also reduced the mRNA expression of iNOS, TNF-a, IL-1 $\beta$, and CINC-1 (Fig. 7B), indicating that OMZ affects these genes at the transcriptional and/or posttranscriptional levels.

\section{Effects of omeprazole on NF-KB activation and iNOS mRNA levels in primary cultured rat hepatocytes.}

Although OMZ had no effects on the degradation of IKBa (Fig. 8A), OMZ inhibited NF-KB activation at 2, 3 , and $4 \mathrm{~h}$ (Fig. 8B1 and 8B2). iNOS mRNA expression is regulated through activation of the iNOS promoter by transcription factors such as NF-KB and through post-transcriptional modifications such as mRNA stabilization ${ }^{33}$. Transfection was performed using pRiNOS-Luc-SVpA and pRiNOS-Luc-3'UTR, which detected iNOS promoter activation (i.e., mRNA synthesis) and mRNA stability, respectively ${ }^{34}$. IL-1 $\beta$ increased the luciferase activity of these vector constructs, and these effects were inhibited by OMZ (Fig. $8 C)$.

\section{Discussion}


In this study, we investigated the liver-protective effects of OMZ using two septic rat models (GaIN/LPS and $\mathrm{PH} / \mathrm{LPS}$ ) as in vivo liver injury models. We also attempted to clarify the protective mechanisms of OMZ in IL-1 $\beta$-stimulated rat hepatocytes in an in vitro liver injury model ${ }^{27}$. OMZ demonstrated hepatoprotective effects in both in vivo models, and our experiments in the in vitro liver injury model indicated several possible mechanisms for these effects.

PPIs such as OMZ are clinically used for the treatment of gastric acid-related disorders including gastroduodenal ulcers, reflux esophagitis, and non-steroidal anti-inflammatory drug (NSAID)-induced gastric lesions. PPIs are also effective on elements of the immune system including monocytes, neutrophils, and endothelial cells ${ }^{35}$. PPIs suppress neutrophil functions such as chemotaxis, superoxide production, and degranulation via IL-8 ${ }^{36}$. In addition, P-type proton-ATPase inhibitors have antiinflammatory effects by reducing neutrophil adhesion molecules and free oxygen radicals ${ }^{37}$. They are also known to activate heme oxyegenase-1 ( $\mathrm{HO}-1$ ), an endogenous antioxidant ${ }^{38}$. We have previously reported these hepatoprotective effects of LPZ, a PPI, because of its ability to induce an anti-oxidative stress response in the liver ${ }^{5}$. Sepsis is a major cause of death and is associated with hypotension (i.e., septic shock) and multiple organ failure, including liver failure ${ }^{1}$. However, the etiology of sepsis has not been completely elucidated and there is no specific treatment. Therefore, determination of the cause of sepsis is especially important in a clinical situation.

In rats, GalN-treatment or $70 \%$ hepatectomy with a sublethal dose of LPS increases the sensitivity to endotoxin. Therefore, these rats induce liver failure ${ }^{39-41}$. NO in the serum starts to increase at $3 \mathrm{~h}$ and further increases until $6 \mathrm{~h}$ after LPS injection ${ }^{4}$. NF-KB, a transcription factor involved in inflammation and apoptosis ${ }^{42}$, mediates this induction, including iNOS stimulation ${ }^{3,4,6}$. The resulting cytokine storm provokes multiple organ failure, including liver failure, which is the result of apoptosis of hepatocytes induced by TNF-a ${ }^{43,44}$. Upregulation of iNOS, TNF-a, and other inflammatory mediators in inflamed hepatocytes is central to liver inflammation. In response to interactions with pathogenic bacteria, inflammatory cells increase the production of these proinflammatory mediators, which in turn activate other processes that promote inflammation.

In rat models of GaIN/LPS and PH/LPS, we reduced the doses of LPS after GalN treatment and $70 \%$ hepatectomy to 2.5 and $25 \mu \mathrm{g} / \mathrm{kg}$, respectively. In these positive controls (without OMZ), lower LPS did not have any effect on survival (less than $10 \%$ or approximately $0 \%$ ) in the GaIN/LPS model, but increased survival (20\%-40\%) in the PH/LPS model (Fig. 1). Under such conditions, 180 and $100 \mathrm{mg} / \mathrm{kg}$ $\mathrm{OMZ}$ enhanced the cumulative survival of GaIN/LPS and PH/LPS rats, respectively (Fig. 2). Biochemical analyses showed that OMZ inhibited the activation of NF-kB (Fig. 3), decreased the mRNA expression of inflammatory mediators (TNF-a, iNOS, CINC-1, IL6 and IL-1 $\beta$ ), increased IL-10 mRNA expression in the liver (Fig. 4), and decreased the production of NO, ALT/AST, TNF-a, IL-6, and IL-1 $\beta$ in serum (Fig. 5). Further histopathological analyses in the liver also showed that OMZ reduced the areas of focal necrosis with inflammatory cell infiltration and massive hemorrhage in GaIN/LPS and PH/LPS rats (Fig. 6), 
whereas MPO experiments demonstrated that OMZ reduced necrosis in both models (Fig. 6B5 and 6E5). However, in TUNEL staining (apoptosis), OMZ reduced apoptosis in GalL/LPS but not PH/LPS rats.

In both models, OMZ had similar liver-protective effects. However, there were some differences between these models. For example, in the case of EMSA (NF-KB activation), positive control rats in the PH/LPS model exhibited less effective increases in NF-KB activation at $4 \mathrm{~h}$, and OMZ had no effect (Fig. $3 \mathrm{~B}$ ). In contrast, at both 1 and $6 \mathrm{~h}$ in the GaIN/LPS model, high increases in NF-KB activation were observed, which were inhibited by OMZ, and IL- 6 and IL-1 $\beta$ were increased at $1 \mathrm{~h}$ in PH/LPS and at $6 \mathrm{~h}$ in GaIN/LPS rats, respectively, which was also inhibited by OMZ. These differences may demonstrate an important indicator for the clinical use of $\mathrm{OMZ}$ in the future.

We next compared OMZ effects in different septic (liver injury) models. The dose and administration method of OMZ (40-240 mg/kg, i.p.; single administration) used in this study differed to the standard clinical use (20 mg/50 kg, i.v.; single administration). These doses were calculated according to those previously used in our experimental studies $(100 \mathrm{mg} / \mathrm{kg} \mathrm{LPZ})^{5}$.

In addition, from the results obtained in in vitro primary cultured rat hepatocytes (Fig. 7 and 8), we confirmed that OMZ inhibited the induction of iNOS in dose-dependent manner, followed by the blockade of excess NO production, which is one of the factors involved in organ injury including that of the liver $8,9,27$. In vitro experiments also revealed that $\mathrm{OMZ}$ reduced the mRNA expression of other proinflammatory mediators (TNF- $\alpha$, IL-1 $\beta$, and CINC-1), in part through the inhibition of NF-KB activation. OMZ decreased the expression of iNOS mRNA and protein through the inhibition of both promoter transactivation (mRNA synthesis) and mRNA stabilization. These findings are consistent with the results of previous studies 45,46 .

The regulation of inflammatory reactions during the perioperative period is important to prevent organ damage and complications. In this study, we investigated the hepatoprotective effects of OMZ using in vivo and in vitro liver injury models. Our experiments showed that $\mathrm{OMZ}$ prevents proinflammatory mediator expression (iNOS, TNF-a, CINC-1, IL-6, and IL-1 $\beta$ ) by suppressing NF-KB activation. In addition, OMZ increased survival in GalN/LPS and PH/LPS rats. These results suggest that OMZ may have a role in preventing liver injury, and further in-depth studies are needed to explore its possible therapeutic applications.

\section{Methods}

Ethics statement. Animal care and experiments were performed in accordance with the standards in the ARRIVE ${ }^{47}$ and PREPARE ${ }^{48}$ guidelines. In addition to these, our study was in accordance with the relevant guidelines and regulations, which was approved by the Animal Care Committee of Kansai Medical University (19-009 and 20-059). Animal models were created in compliance with the criteria of the ARRIVE ${ }^{47}$ and PREPARE ${ }^{48}$ guidelines. All methods proposed in these studies were also carried out according to the standards of relevant institutional guidelines and regulations. 
Drugs. OMZ $(20 \mathrm{mg})$ and recombinant human IL-1 $\beta\left(2 \times 10^{7} \mathrm{U} / \mathrm{mg}\right.$ protein) were purchased from Nichiiko Co., Ltd. (Toyama, Japan) and MyBioSource (San Diego, CA, USA). Isoflurane, pentobarbital sodium, collagenase, Transaminase Cll-test kit, GaIN, 10\% formalin, and PicaGene Luminescence kit were from Wako Pure Chemical Industries (Osaka, Japan). LPS (Escherichia coli; 0111:B4) and mouse anti- $\beta$-tubulin were from Sigma-Aldrich Japan (Tokyo, Japan). Enzyme-linked immunosorbent assay (ELISA) kits were from Life Technologies Japan (Tokyo, Japan). TRIzol $^{\mathrm{TM}}$ Reagent was from Thermo Scientific (Waltham, MA, USA). T4 polynucleotide kinase, Oligo (dT) Primer ( $25 \mathrm{ng}$ ), dNTPs Mixture, RNase Inhibitor, and Rever Tra Ace ${ }^{\circledR}$ were from Toyobo (Osaka, Japan). Beta-Glo kits and mouse immunoglobulin $\mathrm{K}$ light chain were from Promega (Fitchburg, WI, USA).

Animals. Male Wistar and Sprague-Dawley rats were purchased from Charles River Laboratories Japan (Yokohama, Japan) and maintained in a room at $22^{\circ} \mathrm{C}$ under a 12-h light/dark cycle were conducted with a diet of $\mathrm{Y}$-irradiated CRF-1 (Oriental Bioservice, Kyoto, Japan) and water ad libitum.

Rat GaIN/LPS and PH/LPS models. To examine effect of LPS on survival, acute liver injury was induced in the in vivo model. Male Sprague-Dawley rats (8 weeks old, $300 \mathrm{~g} \pm 20$ ) were anesthetized with isoflurane (Abbott Laboratories, Abbott Park, IL, USA) before receiving an i.v. injection of GaIN/LPS (500 $\mathrm{mg} / \mathrm{kg}$ GalN and $0.5-50 \mu \mathrm{g} / \mathrm{kg}$ LPS) via the penile vein ${ }^{49}$. Survival was monitored for 3 days after GalN/LPS injection. To examine the effects of OMZ on survival in the liver injury model with GaIN/LPS $(2.5 \mu \mathrm{g} / \mathrm{kg}$ LPS), rats that were randomly assigned to receive $\mathrm{OMZ}$ were injected (i.p.) with various doses of OMZ (40-240 mg/kg) $1 \mathrm{~h}$ before GalN/LPS treatment. Survival was monitored for 5 days.

To investigate the effects of LPS on survival, the PH/LPS model was induced. Rats were anesthetized with pentobarbital and isoflurane prior to undergoing $70 \%$ hepatectomy, as reported previously 29,50 . Forty-eight hours after surgery, LPS $(6.25-250 \mu \mathrm{g} / \mathrm{kg})$ was injected into the penile vein. Survival was monitored for 3 days after LPS injection. To determine the effects of OMZ levels on survival in the liver injury model with PH/LPS (25 $\mathrm{\mu g} / \mathrm{kg})$, rats were randomly divided into control, OMZ, PH/LPS, and $\mathrm{PH} / \mathrm{LPS}+\mathrm{OMZ}$ groups. Forty-eight hours after surgery, LPS $(25 \mu \mathrm{g} / \mathrm{kg})$ was injected into the penile vein. The rats that were randomly assigned to receive $\mathrm{OMZ}$ were injected (i.p.) with various doses of $\mathrm{OMZ}$ (40$100 \mathrm{mg} / \mathrm{kg}$ ) $1 \mathrm{~h}$ before LPS treatment. Survival was monitored for 5 days. The rats were killed when they appeared weak and moribund because of the progression of liver failure, congestion, and multi-organ failure. We used the NIH Office of Animal Care and Use ${ }^{51}$ score and severity assessment to assess the animals following liver resection ${ }^{52}$. Liver and blood samples were collected from the rats 1 and $6 \mathrm{~h}$ after GaIN/LPS treatment, and 1 and $4 \mathrm{~h}$ after LPS treatment in PH/LPS.

EMSA. EMSA was performed as described previously 53,54 with a minor modification, as described elsewhere ${ }^{6,55}$. Nuclear extracts were prepared from frozen liver at $-80^{\circ} \mathrm{C}$ or cultured hepatocytes. Binding reactions were undertaken by incubating the nuclear extracts in reaction buffer $(20 \mathrm{mM} \mathrm{HEPES}-\mathrm{KOH}, \mathrm{pH}$ 7.9 , containing $1 \mathrm{mM}$ EDTA, $60 \mathrm{mM} \mathrm{KCl}, 10 \%$ glycerol, and $1 \mu \mathrm{g}$ poly[dl-dC]) with a probe $(40,000 \mathrm{dpm})$ for $20 \mathrm{~min}$ at room temperature. Products were electrophoresed on a $4.8 \%$ polyacrylamide gel in high-ionicstrength buffer, and dried gels were analyzed by autoradiography. An NF-kB consensus oligonucleotide 
(5'-AGTTGAG GGGA-CTTTCCCAGGC) from the mouse immunoglobulin $\mathrm{k}$ light chain was purchased and labelled with [Y- $\left.{ }^{32} \mathrm{P}\right]-A T P$ (PerkinElmer, Tokyo, Japan) and T4 polynucleotide kinase. Protein was measured using the Bradford method ${ }^{56}$. Bands corresponding to NF-KB were quantified by densitometry using Image ${ }^{57}$.

Reverse transcriptase-polymerase chain reaction (RT-PCR). Total RNA was extracted from the frozen liver samples or cultured hepatocytes using TRIzol ${ }^{\circledR}$ reagent (the guanidinium thiocyanate-phenol-chloroform mixture) ${ }^{58}$. cDNA was synthesized from $1 \mu$ g total RNA from each sample with Oligo(dT)20 Primer (25 $\mathrm{ng} / \mu \mathrm{L}), 5 \times \mathrm{RT}$ Buffer $(5 \mu \mathrm{L}), 10 \mathrm{mM}$ dNTPs Mixture $(2.5 \mu \mathrm{L})$, RNase Inhibitor (20 units/0.5 $\mu \mathrm{L})$, Rever Tra Ace $(100$ units $/ \mu \mathrm{L})$, and UltraPure ${ }^{\mathrm{TM}}$ DNase/RNase-free distilled water (total volume, $\left.25 \mu \mathrm{L}\right)$. The conditions of thermal cycling using iCycler (Bio-Rad Laboratories, Hercules, CA, USA) were $42^{\circ} \mathrm{C}$ for 60 min and $95^{\circ} \mathrm{C}$ for $5 \mathrm{~min}$. Real-time PCR was performed using SYBR Green and primers for each gene. Primer sequences were synthesized by Eurofins Genomics (Tokyo, Japan) (Table 1). The conditions of thermal cycling using a Rotor-Gene Q (Qiagen, Stanford, VA, USA) were $95^{\circ} \mathrm{C}$ for 5 min followed by 40 cycles of $95^{\circ} \mathrm{C}$ for $5 \mathrm{~s}$ and $60^{\circ} \mathrm{C}$ for $10 \mathrm{~s}$. Collection and analyses of data were undertaken using the system software. mRNA expression levels of each gene were measured as CT threshold levels and normalized to those of eukaryotic elongation factor- $1 \mathrm{a}$. The CDNA sequence for rat NOS2 mRNA was deposited in the DNA Data Bank of Japan/European Bioinformatics Institute/GenBank under accession number AB250951.

Serum biochemical analyses. Serum ALT and AST levels were quantified using commercial kits. The serum levels of nitrite and nitrate (stable metabolites of NO) were measured using a commercial kit (Roche, Mannheim, Germany) according to the Griess method ${ }^{59}$.

Histopathological analyses. Excised liver specimens from the Sprague-Dawley rats were collected and fixed in $10 \%$ formalin and embedded in paraffin. Sections of 3-5 $\mu \mathrm{m}$ in size were cut and stained with HE. Neutrophil infiltration was evaluated by staining with MPO using anti-MPO antibodies (A0398; DAKO, Glostrup, Denmark) before HE staining. Apoptotic bodies in the hepatocyte nuclei were detected by TUNEL staining using an in-situ Apoptosis Detection Kit (MK500; Takara Bio Inc., Kusatsu, Shiga, Japan). The number of MPO- and TUNEL-positive cells per square millimeter was counted by analysts who were blinded to the treatment arm.

Preparation of rat primary cultured hepatocytes. Collagenase perfusion was used to isolate hepatocytes from male Wistar rats (200-250 g, 6-7 weeks old) ${ }^{60,61}$. The isolated hepatocytes were cultured with Williams' medium E (supplemented with $10 \%$ fetal calf serum, HEPES $(5 \mathrm{mmol} / \mathrm{L})$, penicillin $(100 \mathrm{U} / \mathrm{mL})$, streptomycin $(100 \mu \mathrm{g} / \mathrm{mL})$, amphotericin B $(0.25 \mu \mathrm{g} / \mathrm{mL})$, aprotinin $(0.1 \mu \mathrm{g} / \mathrm{mL} ;$ Roche, Basel, Switzerland), dexamethasone (10 nmol/L), and insulin ( $10 \mathrm{nmol} / \mathrm{L})$. After $7 \mathrm{~h}$, the medium was changed with fresh hormone-free medium and the cells were cultured overnight. The number of cells attached to the dishes was estimated by counting the number of nuclei ${ }^{62}$ and applying a ratio of $1.37 \pm 0.04$ nuclei/cell (mean \pm standard error; $n=7$ experiments). 
Treatment of the cultured hepatocytes with OMZ. OMZ was dissolved in Williams' medium E under sterile conditions. On day 1 after cell culture, the hepatocytes were washed with fresh serum- and hormone-free Williams' medium E and incubated with IL-1 $\beta(1 \mathrm{nmol} / \mathrm{L})$ in the same medium, either in the presence or absence of $\mathrm{OMZ}$ (dose range, $0.1-0.5 \mathrm{mmol} / \mathrm{L}$ ).

Determination of NO production and LDH activity in the cultured hepatocytes. The amount of nitrite (a stable metabolite of NO) in the cell culture medium of the hepatocytes was measured using the Griess method ${ }^{59}$. Cell viability was measured on the basis of LDH activity using a commercial kit (Cytotoxicity LDH Assay Kit-WST; Dojindo Inc., Tokyo, Japan).

Western blotting in the cultured hepatocytes. Total cell lysates were obtained from the cultured hepatocytes using a previously described method with minor modifications ${ }^{4,46}$. Immunostaining was performed with primary antibodies against mouse iNOS (Affinity BioReagents, Golden, CO, USA), human inhibitor of KB alpha (IKBa; Santa Cruz Biotechnology, Santa Cruz, CA, USA), and rat $\beta$-tubulin. Immunoreactive proteins were visualized by an enhanced chemiluminescence detection kit (GE Healthcare Biosciences, Piscataway, NJ, USA).

Transfection and luciferase assay in the cultured hepatocytes. Transfection of the cultured hepatocytes was performed using a previously described method ${ }^{63}$. Hepatocytes were cultured at $3 \times 10^{5}$ cells $/$ dish $(35 \times 10 \mathrm{~mm})$ in Williams' medium E with serum, dexamethasone, and insulin for $7 \mathrm{~h}$ before undergoing magnet-assisted transfection. Reporter constructs pRiNOS-Luc-SVpA (for detecting the transactivation of the NOS2 promoter) or pRiNOS-Luc-3'UTR (for detecting the stability of mRNA) (1 $\mu \mathrm{g}$ ) and the cytomegalovirus promoter-driven $\beta$-galactosidase plasmid pCMV-LacZ ( $1 \mathrm{ng}$; internal control) were mixed with a magnet-assisted transfection reagent ( $1 \mu \mathrm{L}$; IBA Lifesciences, Göttingen, Germany) in fresh serumand hormone-free Williams' medium E $(1.5 \mathrm{~mL})$, followed by incubation with cultured cells. After a 15-min incubation period on a magnetic plate at room temperature, the medium was replaced with fresh Williams' medium E with serum. The cells were then cultured overnight and treated with IL-1 $\beta$ in the presence or absence of $\mathrm{OMZ}$.

Statistical analyses. Quantitative results were obtained from three to four independent experiments for each of the various analyses, and the mean values and their standard deviations were calculated. Differences between groups and survival rates were identified using the Student's $t$-test and log-rank test, respectively (JMP® 14 , SAS Institute Inc., Cary, NC, USA). $P<0.05$ was considered significant.

\section{Declarations}

\section{Acknowledgements}

Authors thank Kyodo Byori (Kobe, Japan) for staining the liver specimens, and H. Nikki March, PhD, from Edanz Group (https://en-author-services.edanz.com/ac), for editing a draft of this manuscript. This study was supported by the research fund of the Department of Surgery of Kansai Medical University. 


\section{Authors' contributions}

MKo performed the experiments and acquired and analyzed the data. $\mathrm{YH}$ and $\mathrm{RN}$ helped to generate the GalN/LPS and PH/LPS models under the supervision of MKa and MS. MKo, RN, and TaO wrote the manuscript. $\mathrm{YH}, \mathrm{MH}$, and TY assisted in the primary culture of isolated rat hepatocytes and their analyses. $\mathrm{MN}$ and $\mathrm{TeO}$ helped to the transfection and EMSA experiment (NF-KB activation). TaO was a mentor of this study and attended all experiments. All authors approved the final version of the manuscript for submission.

\section{Competing Interests}

The authors declare no competing interests.

\section{References}

1. Singer, C.S. Deutschman, C.W. Seymour, M. Shankar-Hari, D. Annane, M. Bauer, R. Bellomo, G.R. Bernard, J.-D. Chiche, C.M. Coopersmith, R.S. Hotchkiss, M.M. Levy, J.C. Marshall, G.S. Martin, S.M. Opal, G.D. Rubenfeld, T. van der Poll, J.L. Vincent, D.C. Angus, The third international consensus definitions for sepsis and septic shock (Sepsis-3). JAMA 315, 801-810 (2016).

2. Ogura, S. Gando, D. Saitoh, N. Takeyama, S. Kushimoto, S. Fujishima, T. Mayumi, T. Araki, H. Ikeda, J. Kotani, Y. Miki, S. Shiraishi, K. Suzuki, Y. Suzuki, K. Takuma, R. Tsuruta, Y. Yamaguchi, N. Yamashita, N. Aikawa, Japanese Association for Acute Medicine Sepsis Registry (JAAMSR) Study Group, Epidemiology of severe sepsis in Japanese intensive care units: a prospective multicenter study. J. Infect. Chemother. 20, 157-162 (2014).

3. Hijikawa, M. Karibori, Y. Uchida, M. Yamada, K. Matsui, T. Ozaki, Y. Kamiyama, M. Nishizawa, T. Okumura, Insulin-like growth factor 1 prevents liver injury through the inhibition of TNF-a and iNOS induction in D-galactosamine and LPStreated rats. Shock 29, 740-747 (2008).

4. Tanaka, Y. Uchida, M. Kaibori, T. Hijikawa, M. Ishizaki, M. Yamada, K. Matsui, T. Ozaki, K. Tokuhara, Y. Kamiyama, M. Nishizawa, S. Ito S, T. Okumura, $\mathrm{Na}+\mathrm{H}+$ exchanger inhibitor, FR183998, has protective effect in lethal acute liver failure and prevents iNOS induction in rats. J. Hepatol. 48, 289299 (2008).

5. Nakatake R., Hishikawa H., Kotsuka M., Ishizaki M., Matsui K., Nishizawa M., Yoshizawa K., Kaibori M., Okumura T., The proton pump inhibitor lansoprazole has hepatoprotective effects in in vitro and in vivo rat models of acute liver injury. Dis. Sci. 64, 2854-2866 (2019).

6. Tsuji, A.H. Kwon, H. Yoshida, Z. Qiu, M. Kaibori, T. Okumura, Y. Kamiyama, Free radical scavenger (edaravone) prevents endotoxin-induced liver injury after partial hepatectomy in rats. J. Hepatol. 42, 94-101 (2005).

7. Nakatake R., Tanaka T., Ueyama Y., Miki H., Ishizaki M., Matsui K., Kaibori M., Okumura T., Nishizawa M., Kon M., Protective effects of active hexose correlated compound in a rat model of liver injury after hepatectomy. Functional Foods in Health and Disease 6(11), 702-717 (2016). 
8. Colasanti M., Suzuki H., The dual personality of NO. Trends in Pharmacological Science 21, 249-252 (2000).

9. Iwakiri Y., Kim MY., Nitric oxide in liver diseases. Trends Pharmacol. Sci. 36, 524-536 (2015).

10. Fellenius E., Berglindh T., Sachs G., Olbe L., Elander B., Sjostrand S-E., Wallmark B., Substituted benzimidazoles inhibit gastric acid secretion by blocking $(\mathrm{H}++\mathrm{K}+)$ ATPase. Nature 290, 159-161 (1981).

11. Lind T., Cederberg C., Ekenved G., Haglund U., Olbe L., Effect of omeprazole-a gastric proton pump inhibitoron pentagastrin stimulated acid secretion in man. Gut 24, 270-276 (1983).

12. Wallmark B., Lorentzon P., Larsson H., The mechanism of action of omeprazole-a survey of its inhibitory actions in vitro. Scand. J. Gastroenterol. 20: (Suppl. 108), 37-51 (1985).

13. Andersson T., Pharmacokinetics of omeprazole in man: with special reference to single and repeated administration, drug interactions and polymorphic metabolism. Ph. D. Thesis. University of Goteborg, Sweden, http://hdl.handle.net/2077/11593 (1991).

14. Stedman CA., Barclay ML., Review article: comparison of the pharmacokinetics, acid suppression and efficacy of proton pump inhibitors. Pharmacol. Ther. 14, 963-978 (2000).

15. Wakabayashi N., Dinkova-Kostova A.T., Holtzclaw W.D. et al. Protection against electrophile and oxidant stress by induction of the phase 2 response: fate of cysteines of the Keap 1 sensor modified by inducers. Natl. Acad. Sci. USA. 101, 2040-2045 (2004).

16. Eggler A.L., Gay K.A., Mesecar A.D., Molecular mechanisms of natural products in chemoprevention: induction of cytoprotective enzymes by Mol. Nutr. Food Res. 52: (Suppl. 1), S84-94 (2008).

17. Numazawa S., Ishikawa M., Yoshida A., Tanaka S., Yoshida T., Atypical protein kinase C mediates activation of NF-E2-related factor 2 in response to oxidative stress. J. Physiol. Cell Physiol. 285, C334-342 (2003).

18. Keum Y.S., Regulation of the Keap1/Nrf2 system by chemopreventive sulforaphane: implications of posttranslational modifications. N. Y. Acad. Sci. 1229, 184-189 (2011).

19. Shay K.P., Moreau R.F., Smith E.J., Smith A.R., Hagen T.M., Alpha-lipoic acid as a dietary supplement: molecular mechanisms and therapeutic potential. Biophys. Acta 1790, 1149-1160 (2009).

20. Hayes J.D., McMahon M., Molecular basis for the contribution of the antioxidant responsive element to cancer chemoprevention. Cancer Lett. 174, 103-113 (2001).

21. Kawai H., Kudo N., Kawashima Y., Mitsumoto A., Efficacy of urine bile acid as a non-invasive indicator of liver damage in rats. Toxicol. Sci. 34, 27-38 (2009).

22. Ueda K., Ueyama T., Oka M., Ito T., Tsuruo Y., Ichinose M., Polaprezinc (Zinc L-carnosine) is a potent inducer of anti-oxidative stress enzyme, heme oxygenase ( $\mathrm{HO})-1$ - a new mechanism of gastric mucosal protection. Pharmacol. Sci. 110, 285-294 (2009).

23. Yamamoto Y., Tanahashi T., Kawai T. et al. Changes in behavior and gene expression induced by caloric restriction in C57BL/6 mice. Genomics. 39, 227-235 (2009). 
24. Ueyama T., Yamamoto Y., Ueda K. et al. Is gastrectomy-induced high turnover of bone with hyperosteoidosis and increase of mineralization a typical osteomalacia? PLoS One 8, e65685 (2013).

25. Strand D.S., Kim D., Peura D.A., 25 years of proton pump inhibitors: a comprehensive review. Gut Liver 11(1), 27-37 (2017).

26. Scarpignato G., Pelosini I., Di. Mario F., Acid suppression therapy: where do we go from here? Dig. Dis. 24 (1-2), 11-46 (2006).

27. Kaibori M., Okumura T., Sato K., Nishizawa M., Kon M., Inducible Nitric Oxide Synthase Expression in Liver Injury: Liver Protective Effects on Primary Rat Hepatocytes. Allergy Drug Targets. 14, 77-83 (2015).

28. Tanaka Y., Kaibori M., Miki H., Nakatake R., Tokuhara K., Nishizawa M., Okumura T., Kwon A.H., Alpha-lipoic acid exerts a liver-protective effect in acute liver injury rats. J. Surg. Res. 193(2), 675-83 (2015).

29. Sakaguchi T., Hashimoto Y., Matsushima H., Hishikawa H., Nishizawa N., Okumura T., Kaibori M., Levosimendan pretreatment improves survival of septic rats after partial hepatectomy and suppresses iNOS induction in cytokine-stimulated hepatocytes. Scientific Reports 9, 13398 (2019).

30. Tavish D., Buckley M.T., Heel R.C., Omeprazole; an updated review of its pharmacology and therapeutic use in acid related disorders. Drugs 42, 138-170 (1991).

31. Andersson T., Miners J.O., Veronese M.E. et al. Identification of human liver cytochrome P450 isoforms mediating omeprazole metabolism. Br. J. Clin. Pharmacol. 36, 521-530 (1993).

32. Kitade H., Sakitani K., Inoue K. et al. Interleukin 1 beta markedly stimulates nitric oxide formation in the absence of other cytokines or lipopolysaccharide in primary cultured rat hepatocytes but not in Kupffer cells. Hepatology 23, 797-802 (1996).

33. Kleinert H., Pautz A., Linker K., Schwarz P.M., Regulation of the expression of inducible nitric oxide synthase. European Journal of Pharmacology 500, 255-266 (2004).

34. Yoshigai E., Hara T., Inaba H. et al. Interleukin-1 $\beta$ induces tumor necrosis factor-a secretion from rat hepatocytes. Res. 44, 571-583 (2014).

35. Wandall J.H., Effects of omeprazole on neutrophil chemotaxis, superoxide production, degranulation, and translocation of cytochrome b-245. Gut 33(5), 617-21, https://doi.org/10.1136/gut.33.5.617 (1992).

36. Ubagai T., Koshibu Y., Koshio O., Nakaki T., Ono Y., Downregulation of immunomodulator gene expression in LPS-stimulated human polymorphonuclear leukocytes by the proton pump inhibitor lansoprazol. J. Infect. Chemother. 15, 374-9, https://doi.org/10.1007/s10156-009-0728-2(2009).

37. Bicakci U., Tander B., Ariturk E. et al. Effects of omeprazole and gentamicin on the biochemical and histopathological alterations of the hypoxia/reoxygenation induced intestinal injury in newborn rats. Pediatr. Surg. Int. 21(10), 800-805, https://doi.org/10.1007/s00383-005-1538-y(2005).

38. Becker J.C., Grosser N., Waltke C. et al. Beyond gastric acid reduction: proton pump inhibitors induce heme oxygenase-1 in gastric and endothelial cells. Biochem. Biophys. Res. 345(3), 1014-1021, 
https://doi.org/10.1016/j.bbrc.2006.04.170(2006).

39. Li J., Billiar T.R., Nitric oxide. IV. Determinants of nitric oxide protection and toxicity in liver. Am. J. Physiol. 276, G1069-G1073 (1999).

40. Arii S., Shibagaki M., Takahashi Y., Taki Y., Yokoo N., Jikko A. et al. Changes in the reticuloendothelial phagocytic function after partial hepatectomy. J. Lab. Clin. Med. 105, 668-672 (1985).

41. Mochida S., Ogata I., Hirata K., Ohta Y., Yamada S., Fujiwara K., Provocation of massive hepatic necrosis by endotoxin after partial hepatectomy in rats. Gastroenterology 99, 771-777 (1990).

42. Lawrence, The nuclear factor NF-kB pathway in inflammation, Cold Spring Harb. Perspect. Biol. 1, a001651 (2009).

43. Nagaki, H. Moriwaki, Implication of cytokines: roles of tumor necrosis factor-a in liver injury. Hepatol. Res. 38 (Suppl. 1), S19-S28 (2008).

44. Kondo, T. Suda, H. Fukuyama, M. Adachi, S. Nagata, Essential roles of the Fas ligand in the development of hepatitis. Nat. Med. 3, 409-413 (1997).

45. Nakamura M., Matsui H., Serizawa H., Tsuchimoto K., Lansoprazole Novel Effector Sites Revealed by Autoradiography: Relation to Helicobacter pylori, Colon, Esophagus and Others. Clin. Biochem. Nutr. 41, 154-159 (2007).

46. Nakanishi H., Kaibori M., Teshima S. et al. Pirfenidone inhibits the induction of iNOS stimulated by interleukin-1 beta at a step of NF-kappaB DNA binding in hepatocytes. Hepatol. 41, 730-736 (2004).

47. Kilkenny C., Browne W.J., Cuthill I.C., Emerson M., Altman D.G., Improving bioscience research reporting: the ARRIVE guidelines for reporting animal research. PLoS Biol. 8, e1000412 (2010).

48. Smith A.J., Clutton R.E., Lilley E., Hansen K.E.A., Brattelid T., PREPARE: guidelines for planning animal research and testing. Anim. 52, 135-141 (2018).

49. Inoue T., Horiai H., Aoki C. et al. Insulin-like growth factor-I prevents lethal acute liver failure induced by D-galactosamine and lipopolysaccharide in rats. In Vivo. 17, 293-299 (2003).

50. Higgins, G. M. \& Anderson, R.M., Experimental pathology of the liver. Arch. Pathol. 12, 186-202 (1931).

51. Guidelines for endpoints in animal study proposals. Office of Animal Care and Use, NIH http://oacu.od.nih.gov/ARAC/Endpoints.pdf

52. Kanzler S., Rix A., Czigany Z. et al. Recommendation for severity assessment following liver resection and liver transplantation in rats. Part I Lab. Anim. 50, 459-467 (2016).

53. Essani N. A., McGuire G. M., Manning A. M. \& Jaeschke H., Endotoxin-induced activation of the nuclear transcription factor B and expression of E-selectin messenger RNA in hepatocytes, Kupffer cells, and endothelial cells in vivo. Immunol. 156, 2956-2963, http://www.jimmunol.org/content/156/8/2956(1996).

54. Schreiber E.,Matthias P., Müller M. M. \& Schaffner W., Rapid detection of octamer binding proteins with mini-extracts, prepared from a small number of cells. Nucleic Acids Res. 17, 6419 (1989). 
55. Oda M., et al. Vicinal dithiol-binding agent, phenylarsine oxide, inhibits inducible nitric oxide synthase gene expression at a step of nuclear factor-kB DNA binding in hepatocytes. Biol. Chem. 275, 43694373, http://www.jbc.org/content/275/6/4369.long(2000).

56. Bradford M. M., A rapid and sensitive method for the quantitation of microgram quantities of protein utilizing the principle of protein-dye binding. Biochem. 72, 248-254, https://doi.org/10.1016/00032697(76)90527-3(1976).

57. Rasband W. S., ImageJ, U. S. National Institutes of Health, Bethesda, Maryland, USA. http://imagej.nih.gov/ij/(1997-2015).

58. Chomczynski P. \& Sacchi N., Single-step method of RNA isolation by acid guanidinium thiocyanatephenol-chloroform extraction. Biochem. 162, 156-159, https://doi.org/10.1016/00032697(87)90021-2(1987).

59. Green L.C., Wagner D.A., Glogowski J., Skipper P.L., Wishnok J.S., Tannenbaum S.R., Analysis of nitrate, nitrite, and [15N] nitrate in biological fluids. Biochem. 126, 131-138 (1982).

60. Seglen P.O., Preparation of isolated rat liver cells. Methods Cell Biol. 13, 29-83 (1976).

61. Kanemaki T., Kitade H., Hiramatsu Y., Kamiyama Y., Okumura T., Stimulation of glycogen degradation by prostaglandin E2 in primary cultured rat hepatocytes. Prostaglandins 45, 459-474, https://doi.org/10.1016/0090-6980(93)90122-N(1993).

62. Horiuti Y., Ogishima M., Yano K., Shibuya Y., Quantification of cell nuclei isolated from hepatocytes by cell lysis with nonionic detergent in citric acid. Cell Struct. Funct. 16, 203-207, https://doi.org/10.1247/csf.16.203 (1991).

63. Matsui K., Kawaguchi Y., Ozaki T. et al. Effect of active hexose correlated compound on the production of nitric oxide in hepatocytes. Journal of Parenteral and Enteral Nutrition 31, 373-380, https://doi.org/10.1177/0148607107031005373(2007).

\section{Table}

\section{Table 1. Primer sets for RT-PCR}

(ㅁp).

EF-1 $\alpha$ oligo (dT) 20 5'-TCTGGTTGGAATGGTGACAACATGC-3'

5'-CCAGGAAGAGCTTCACTCAAAGCTT-3' 
IL-6 oligo (dT)20 5'-GAGAAAAGAGTTGTGCAATGGCA-3'

5'-TGAGTCTTTTATCTCTTGTTTGAAG-3'

286

CINC-1

$\underline{245}$

EF-1 $\alpha$, elongation factor-1-alpha; iNOS, inducible nitric oxide synthase; TNF- $\alpha$, tumor necrosis factor-alpha; IL-1 $\beta$, interleukin-1 beta; IL-6, interleukin-6; CINC-1 (CXCL-1), cytokine-induced neutrophil chemoattractant 1 (chemokine (C-X-C motif) ligand 1); IL-10, interleukin-10.

\section{Figures}

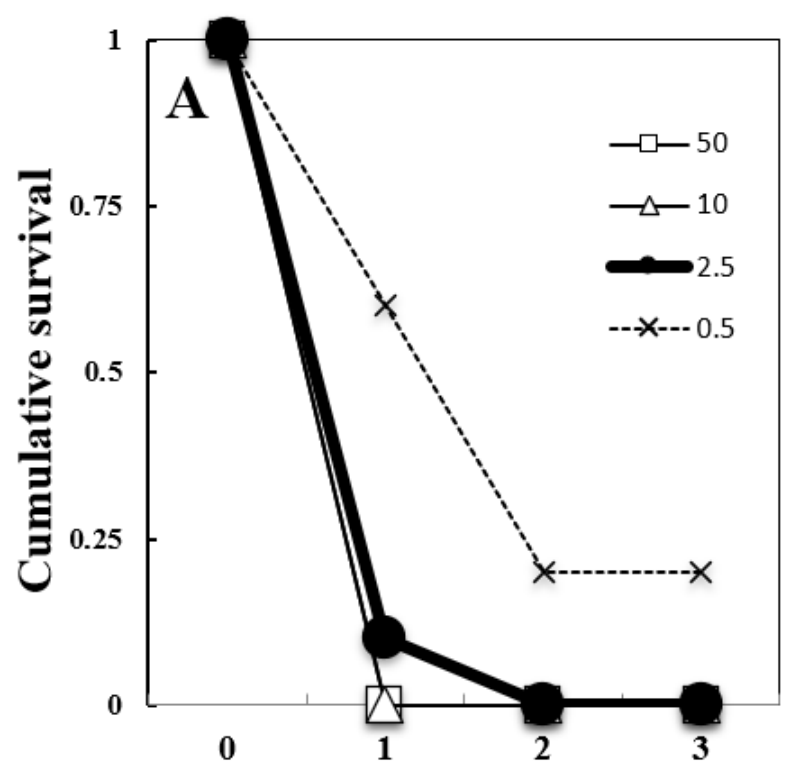

Time after GalN/LPS injection (day)

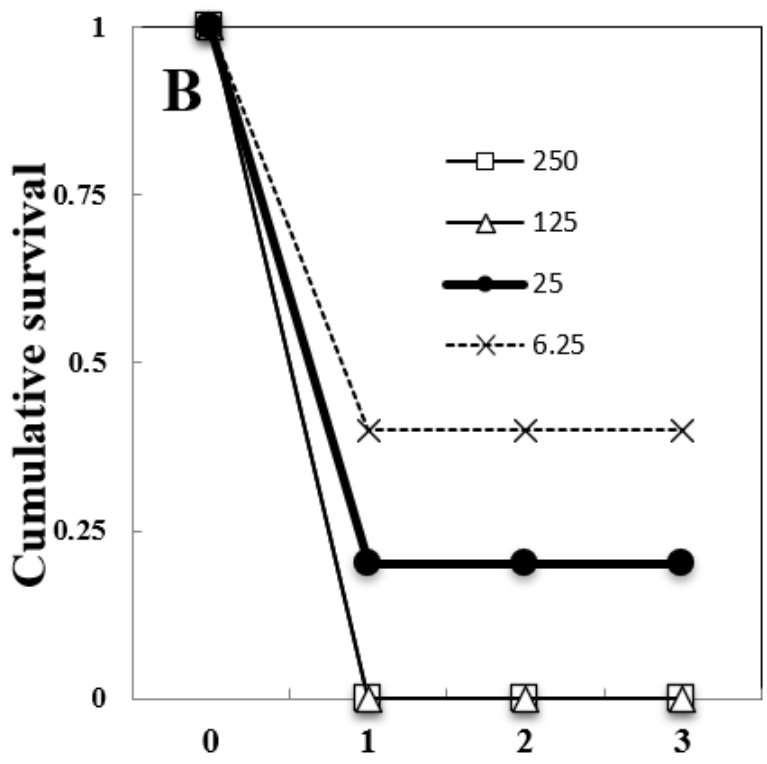

Time after LPS injection (day)

\section{Figure 1}

Survival rates in rat GaIN/LPS and PH/LPS models with various concentrations of LPS. Survival rates in rat GaIN/LPS (A) and PH/LPS (B) models were examined following treatment with various concentrations of LPS (injected into the penile vein, i.v.). (A) $0.5(x, n=13), 2.5(\bullet, n=13), 10(\triangle, n=13)$, and $50(\square, n=13) \mu \mathrm{g} / \mathrm{kg}$ LPS. (B) $6.25(x, n=10), 25(\bullet, n=10), 125(\triangle, n=10)$, and $250(\square, n=10)$ 
$\mu \mathrm{g} / \mathrm{kg}$ LPS. GalN, 500 mg D-galactosamine/kg rat; PH, 70\% hepatectomy; LPS, lipopolysaccharide ( $\mu \mathrm{g}$ of LPS/kg rat).
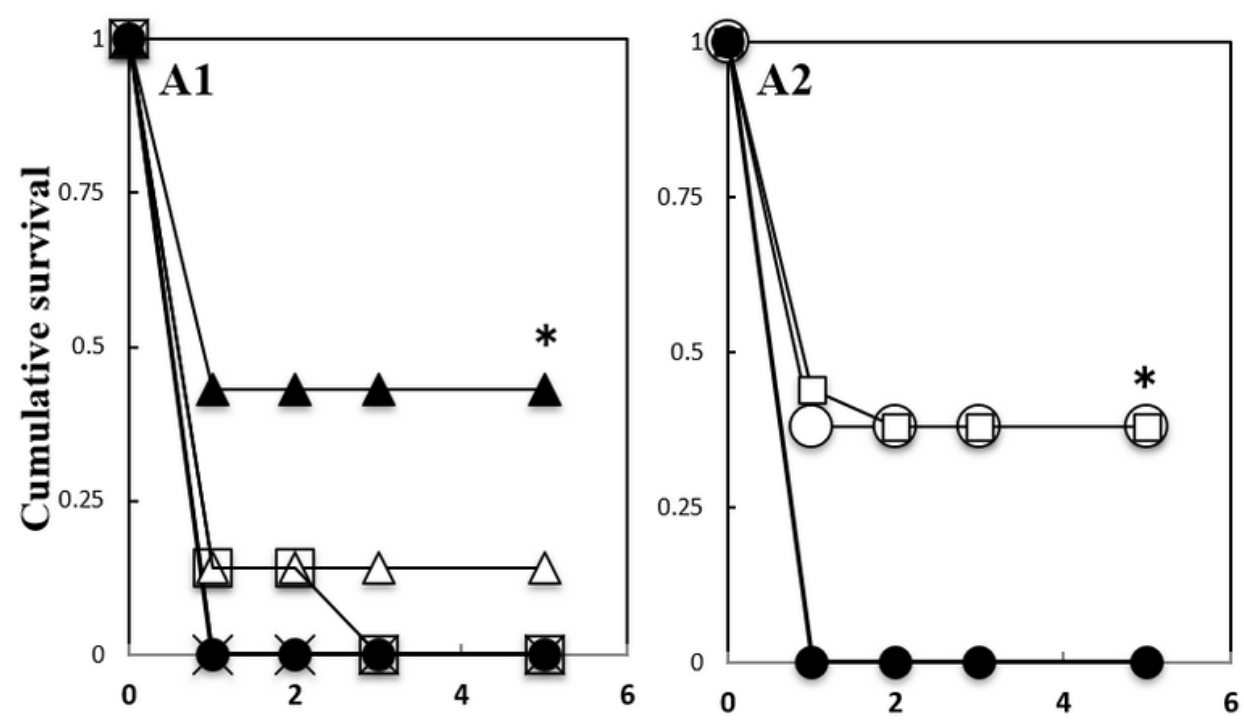

Time after GalN/LPS injection (day)

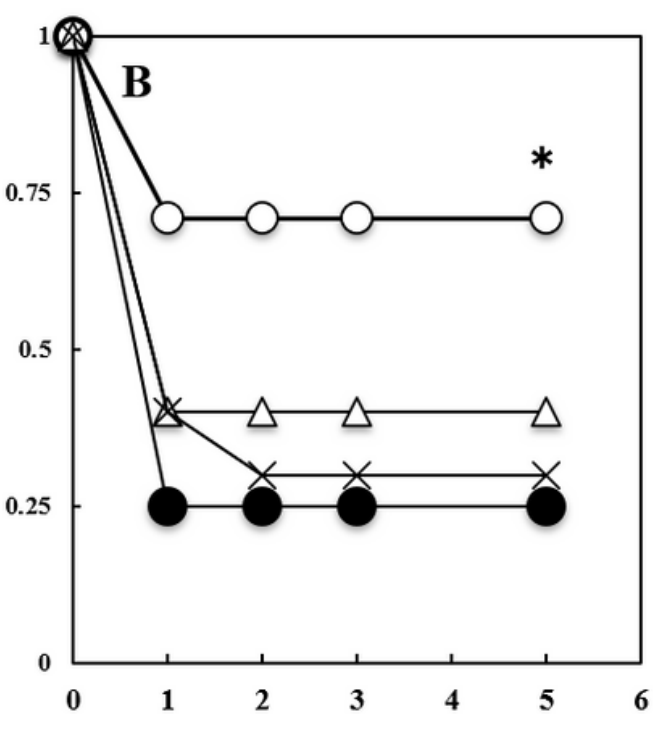

Time after LPS injection (day)

Figure 2

Increased survival in rat GaIN/LPS and PH/LPS models following omeprazole treatment. (A) Positive control (PC): GalN/LPS (2.5 $\mu \mathrm{g} / \mathrm{kg}, 0, n=10$, i.v.); (A1) PC + $40(x, n=5), 80(\triangle, n=13), 120(\square, n=12)$, $120(\times 2)(\Lambda, n=12)$, and (A2) PC + $180(\bullet, n=10)$, and $240 \mathrm{mg}(\square, \mathrm{n}=12)$ omeprazole $(\mathrm{OMZ}) / \mathrm{kg}(\mathrm{OMZ}$ was administered $1 \mathrm{~h}$ before GaIN/LPS treatment; intraperitoneally, i.p.). In cases with two injections (120 $(\times 2))$, the second injection was administered $3 \mathrm{~h}$ after GalN/LPS. (B) PC: PH/LPS $(25 \mu \mathrm{g} / \mathrm{kg}, \boldsymbol{0}, \mathrm{n}=10$, i.v.); $P C+40(x, n=10), 80(\triangle, n=10)$, and $100 \mathrm{mg}(\bullet, n=7) 0 M Z / k g(O M Z$ was administered $1 \mathrm{~h}$ before LPS treatment, i.p.). ${ }^{*}<0.05$ vs. $P C$. 
A

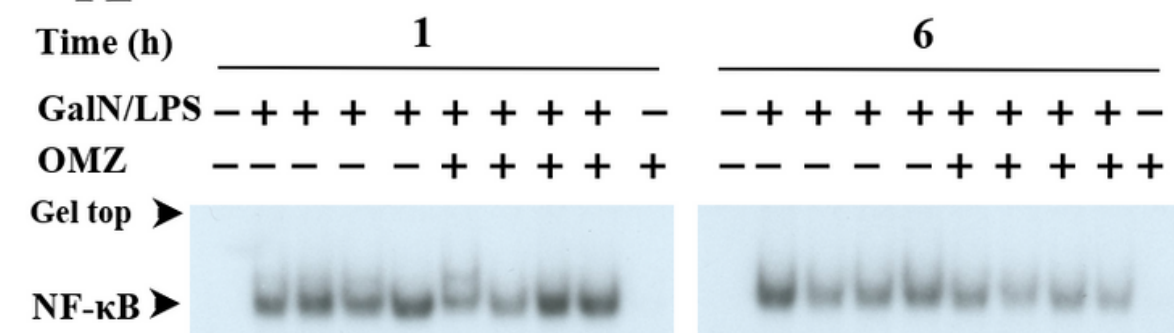

Free probe

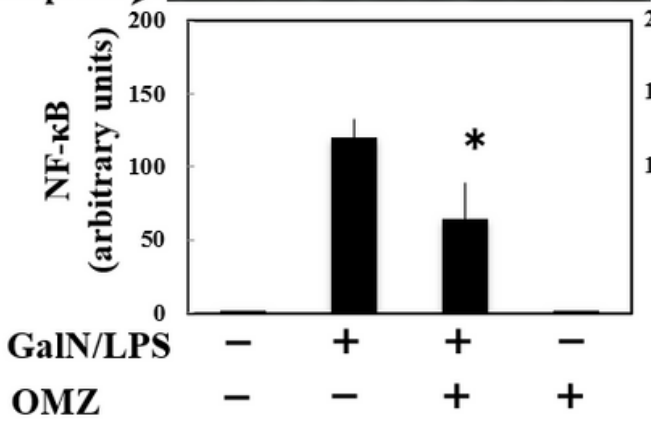

B

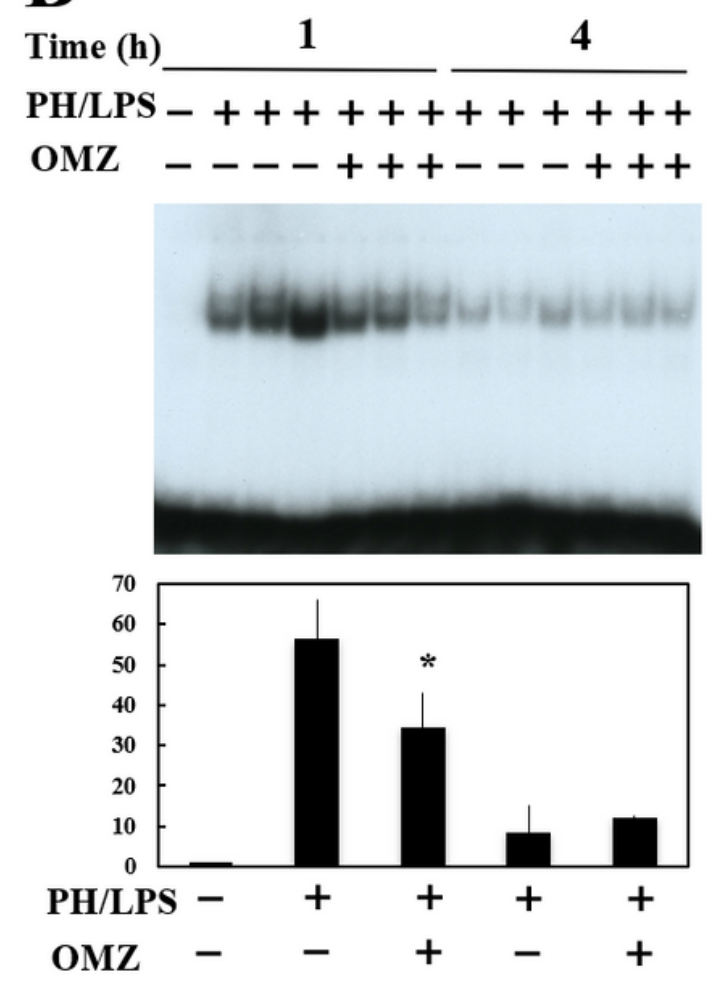

Figure 3

Effects of omeprazole on the activation of NF-KB in the livers of rat GalN/LPS and PH/LPS models. OMZ, omeprazole. (A) GalN (500 mg/kg)/LPS (2.5 $\mu \mathrm{g} / \mathrm{kg}) \pm$ OMZ (180 mg/kg). (B) PH (70\% hepatectomy)/LPS $(25 \mu \mathrm{g} / \mathrm{kg}) \pm \mathrm{OMZ}(100 \mathrm{mg} / \mathrm{kg}) .{ }^{*} \mathrm{P}<0.05 \mathrm{vs}$. PC.
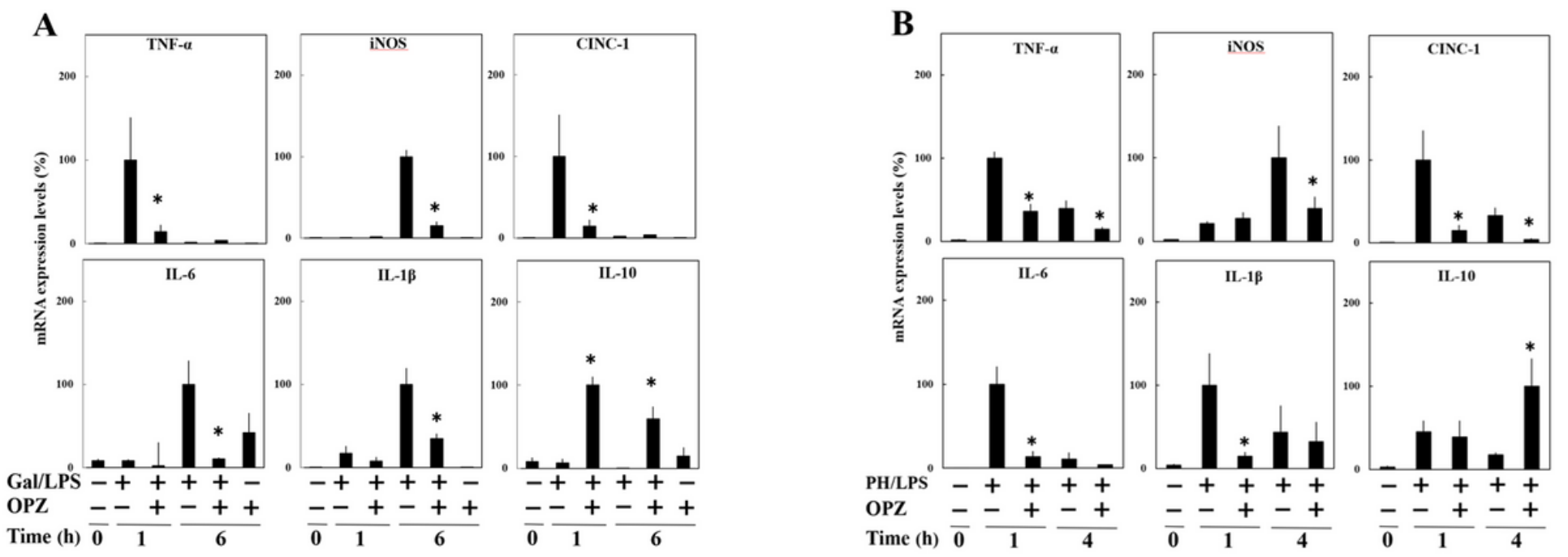

Figure 4

Effects of omeprazole on the mRNA expression of inflammatory mediators in the liver of rat GaIN/LPS and PH/LPS models. OMZ, omeprazole. (A) GalN/LPS. (B) PH/LPS. * $<<0.05$ vs. positive control ( $n=3-$ 5). TNF-a, tumor necrosis factor-alpha; iNOS, inducible nitric oxide synthase; CINC-1, cytokine-induced 
neutrophil chemoattractant-1; IL-6, interleukin-6; IL-1 $\beta$, interleukin-1 beta; IL-10, interleukin-10. *P< 0.05 vs. PC.
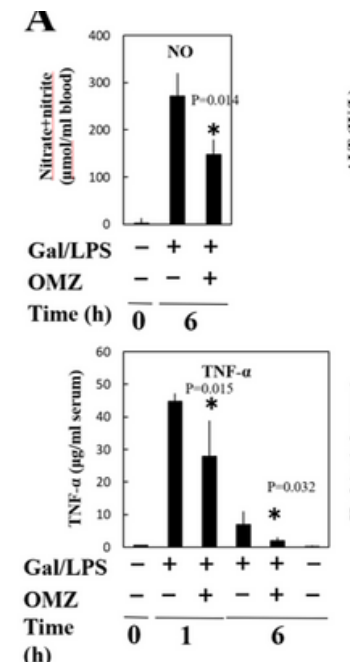
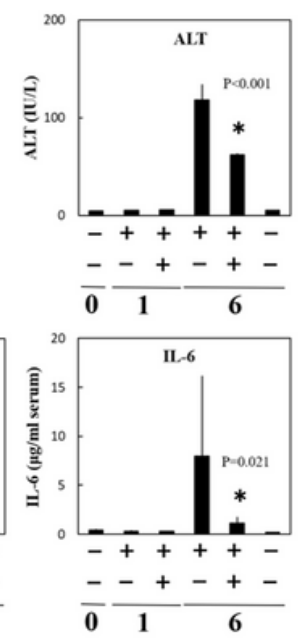
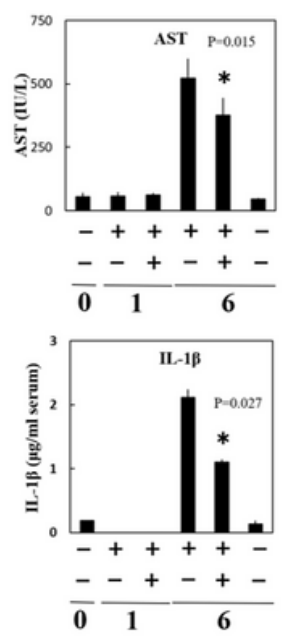

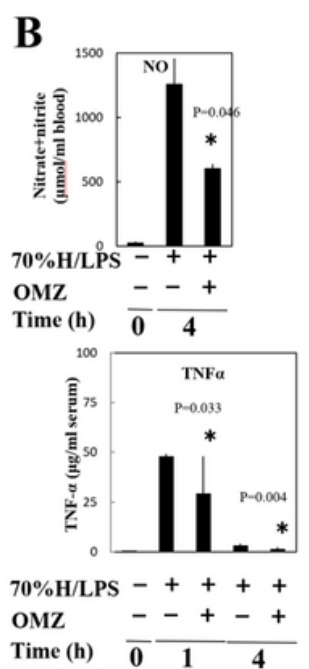

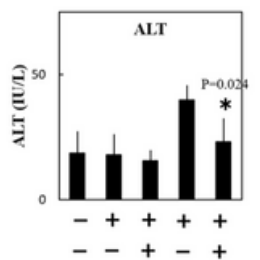
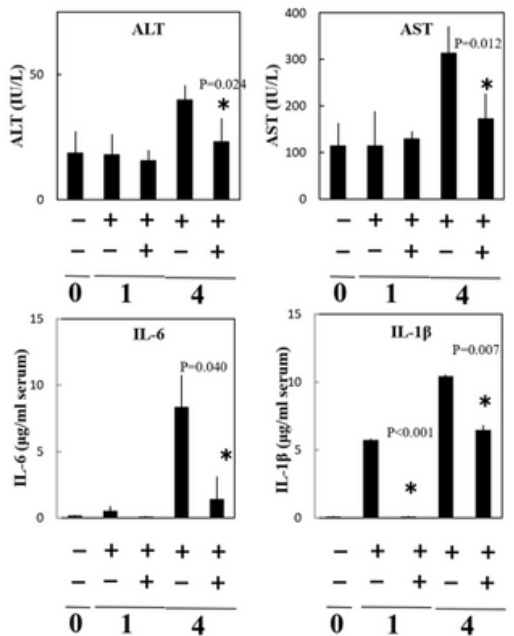

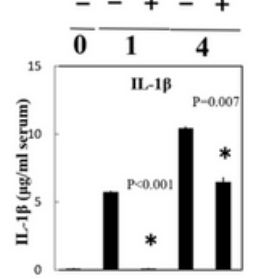

$-++++$

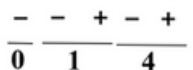

\section{Figure 5}

Effects of omeprazole on nitric oxide, alanine/aspartate transaminases, and cytokines in the serum of rat GalN/LPS and PH/LPS models. OMZ, omeprazole. (A) GalN/LPS. (B) PH/LPS. NO, nitric oxide; ALT/AST, alanine/aspartate transaminases; TNF- $a$, tumor necrosis factor-alpha; IL-6, interleukin-6; IL-1 $\beta$, interleukin1beta. ${ }^{*} \mathrm{P}<0.05$ vs. positive control $(n=3-5)$.
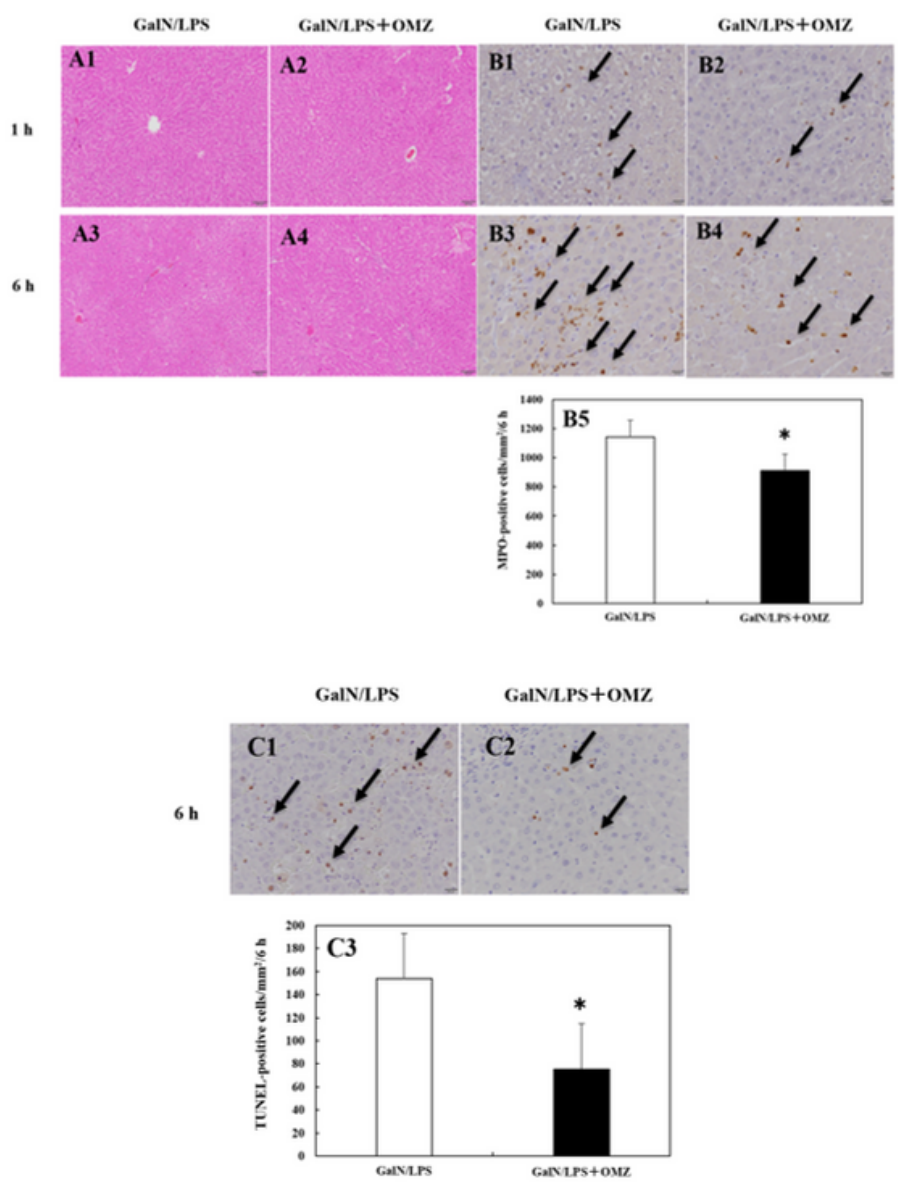
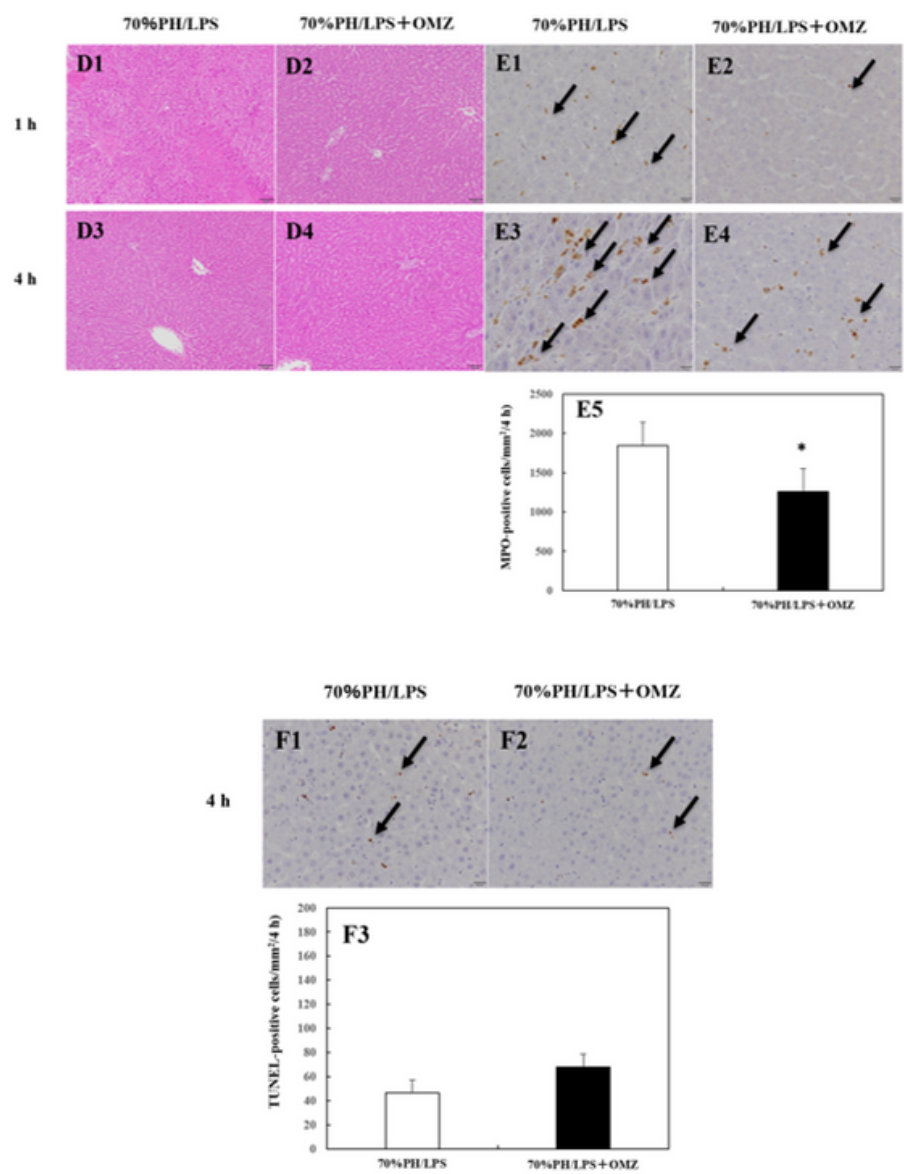
Figure 6

Effects of omeprazole on pathological changes in the livers of GalN/LPS and PH/LPS models.

Omeprazole (OMZ, 180 and $100 \mathrm{mg} / \mathrm{kg}$ ) was administered (i.p.) $1 \mathrm{~h}$ before GalN/LPS and LPS treatments and liver sections were stained in GaIN/LPS (A-C; $1 \mathrm{~h}$ and $6 \mathrm{~h}$ ) and PH/LPS (D-F; $1 \mathrm{~h}$ and $4 \mathrm{~h}$ ) rats, respectively. $\mathrm{H} \& \mathrm{E}$; note the areas of focal necrosis with inflammatory cell infiltration and massive hemorrhage in both rats (A1-4; GalN/LPS and D1-4; PH/LPS). MPO (necrosis); B1-5; GalN/LPS and E1-5; PH/LPS. TUNEL (apoptosis); C1-3; GaIN/LPS and F1-3; PH/LPS. Note the brown nuclei in the positive cells (arrows: positive cells, bar $=100$ microns, magnification $\times 200$ ). The numbers of MPO- and TUNELpositive cells per square millimeter were counted at $6 \mathrm{~h}$ (B5 and C3) in GaIN/LPS and at $4 \mathrm{~h}$ in PH/LPS (E5 and F3). The values in the bar graphs represent the mean \pm standard error $(n=4$ rats per time-point per group). ${ }^{*} \mathrm{P}<0.05$ vs PC (GalN/LPS or PH/LPS).
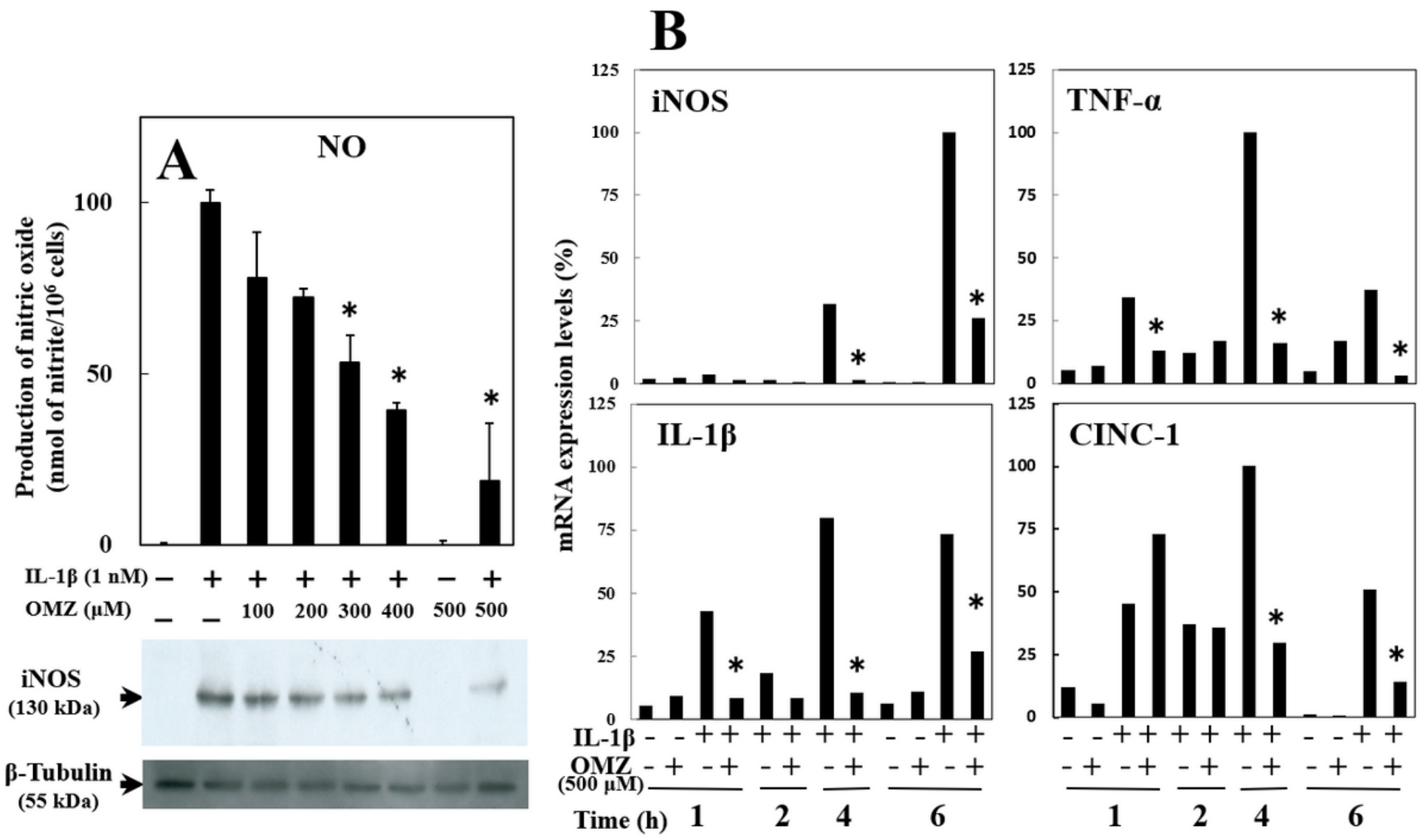

Figure 7

Effects of omeprazole on nitric oxide production, iNOS protein expression, and inflammatory mediator mRNA expression in rat primary cultured hepatocytes. (A) nitric oxide (NO, upper) and iNOS protein (middle). (B) mRNA expression of iNOS, TNF-a, IL-1 $\beta$, and CINC-1. * $\mathrm{P}<0.05$ vs IL-1 3 . OMZ, omeprazole. 

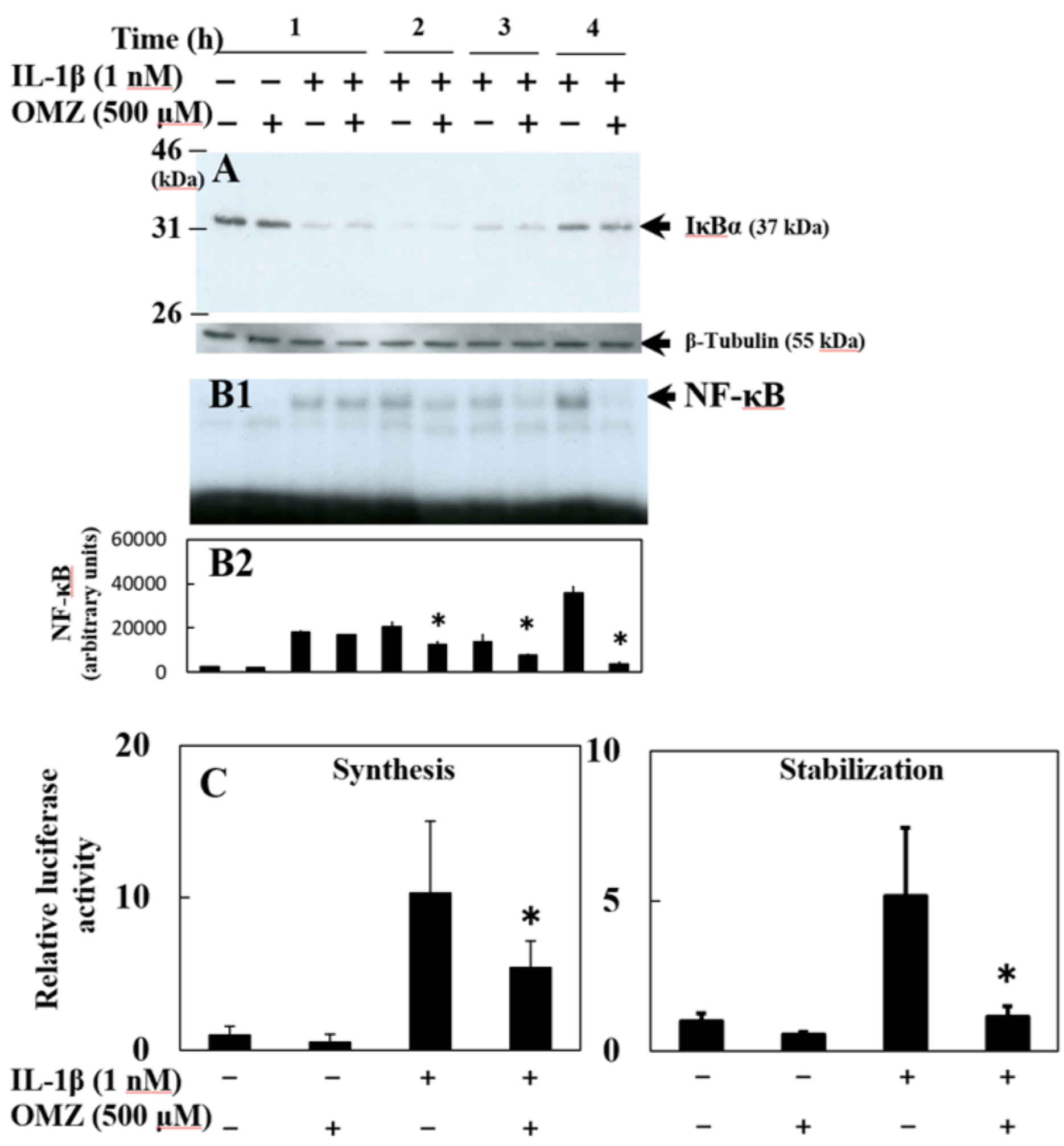

\section{Figure 8}

Effects of omeprazole on NF-KB activation and iNOS mRNA levels in primary cultured rat hepatocytes. (A) IKBa degradation, (B) NF-KB activation (electrophoretic mobility shift assay (B1) and densitometry (B2)), and (C) transfection experiments: iNOS mRNA synthesis (pRiNOS-Luc-SVpA) and its stabilization (pRiNOS-Luc-3'UTR). OMZ, omeprazole. * $\mathrm{P}<0.05$ vs. IL-1ß. 


\section{Supplementary Files}

This is a list of supplementary files associated with this preprint. Click to download.

- Supplementarymaterial.pdf 